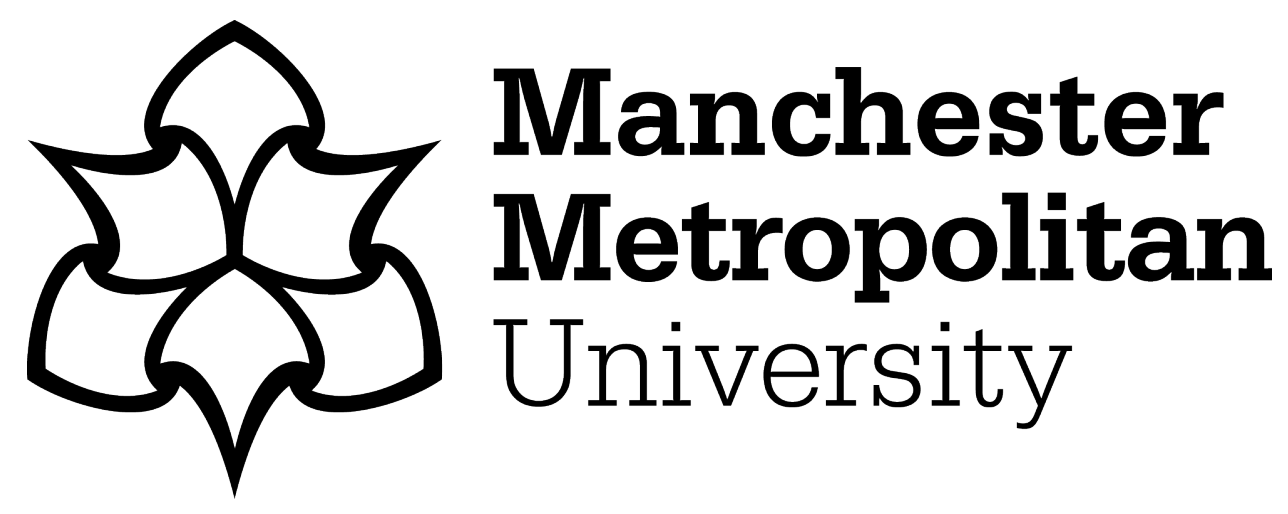

Ibrahim, GR and Albarbar, A ORCID logoORCID: https://orcid.org/00000003-1484-8224 (2019) A new approach to the cohesive zone model that includes thermal effects. Composites Part B: Engineering, 167. pp. 370376. ISSN 1359-8368

Downloaded from: https://e-space.mmu.ac.uk/623539/

Version: Accepted Version

Publisher: Elsevier

DOI: https://doi.org/10.1016/j.compositesb.2019.03.003

Usage rights: Creative Commons: Attribution-Noncommercial-No Derivative Works 4.0

Please cite the published version 


\title{
A New Approach to the Cohesive Zone Model that Includes Thermal Effects
}

\author{
Ghalib R. Ibrahim*, A. Albarbar
}

AdvanSchool of Engineering, Manchester Metropolitan University, Manchester M1 5GD, UK

\begin{abstract}
This study presents a cohesive zone model combining mechanical and thermal effects. Thermal stress was added to the Helmholtz free energy density in order to derive a new approach to incremental damage which included the effect of temperature. The developed damage model has been implemented in ABAQUS using the UMAT subroutine and applied of two different specimens; a three-point bending specimen and a Double Cantilever Beam. The effectiveness of the new method was tested for the given specimens at different temperatures. The simulation results revealed that the total energy of the interface element of high strength carbon fiber reinforced plastic increased as its temperature decreased. It is demonstrated that the loaddisplacement curves obtained from the numerical model for both test specimens were in good agreement with experimental data available in literature.
\end{abstract}

Keywords: Cohesive zone model; Thermal stress; Total energy; UMAT subroutine. 


\section{Introduction}

Composite materials offer many advantages compared to metals and metal-alloys due to their superior mechanical performance, especially where high strength and stiffness to weight ratios are concerned. Thus, advanced composite structures have been widely used in several industrial sectors such as aerospace, rotor blades in wind-energy systems, sport equipment, automotive parts, pressure vessels, among many other applications. However, static, dynamic or thermal load conditions may induce different forms of damage in composite structures which may then exhibit brittle behaviour. This can seriously degrade the stiffness of the component which then provides little damage resistance. And, of course, the load-carrying capability of composite materials decreases if internal damage is present. Modelling the progressive damage of composite materials under different load conditions is an important area, especially with, say, the rotor blades in wind-energy systems where barely visible impact damage can be a critical issue. The demand for high-performance laminated composite materials, especially with regard to long fatigue life, complex geometries and low temperature processing, requires the development of modelling tools that can reliably predict progressive damage, including damage occurring from a range of physical mechanisms (Shi et al. 2012) and (Reinoso et al. 2017).

(Reed and Golda 1994) investigated the effect of cryogenic temperature $\left(-196^{\circ} \mathrm{C}\right)$ on unidirectional CFRP laminates. Their experiments were performed under tensile and compressive loads, and the results indicated that the elastic modulus of CFRP increased by about $10 \%$ at a temperature of $-196^{\circ} \mathrm{C}$. It was also noted that the tensile strength was enhanced at this low temperature.

(Rio et al. 2005) carried out low impact velocity tests on square carbon fibre /epoxy (CFRP) laminates with different stacking sequences (e.g. unidirectional, woven and cross ply) at temperatures ranging from room temperature down to $-150^{\circ} \mathrm{C}$. The specimens were tested using a drop weight tower device. The experimental results showed that there was a clear damage dependency on temperature and laminate type.

(Boominathan et al. 2014) used unidirectional and cross-ply (0/90) carbon/epoxy laminates subject to impacts with energy of $2.17 \mathrm{~J}$ at temperatures $30^{\circ} \mathrm{C}, 55^{\circ} \mathrm{C}, 75^{\circ} \mathrm{C}$ and $90^{\circ} \mathrm{C}$. They found the percentage reduction in flexural strength for both cross ply and unidirectional laminates impacted at high temperature is lower than those tested at room temperature. 
(Amaro et al. 2016) tested CFRP subject to single and multiple impact events. Two impact energies were used ( $1 \mathrm{~J}$ and $3 \mathrm{~J}$ ) and the experiments were carried out at three different temperatures. It was observed that the temperature had a strong effect on matrix properties (stiffness and strength) and on the impact bending stiffness when low energy impacts were used, but that at the higher impact energy, the influence of temperature vanished. The number of impacts to failure remained constant at about four for impact energy of $3 \mathrm{~J}$, but decreased with increase in temperature for impact energy of $1 \mathrm{~J}$, from about twenty at room temperature to about fourteen at $90^{\circ} \mathrm{C}$.

(Jia et al. 2018) studied the influence of temperature on the mechanical properties of CFRP using the three-point bending test. The experiments were performed under static and dynamic loads over the temperature range $-100^{\circ} \mathrm{C}$ to $100^{\circ} \mathrm{C}$. Experimental findings showed relatively poor performance when unidirectional laminated composite were tested at the high temperature, but that the mechanical properties (e.g. energy absorption, flexural strength and maxi mum deflection) were significantly enhanced at the low temperature.

(Wang et al. 2018) performed an experimental investigation of the behaviour of woven carbon fabric/polyphenylene sulfide (CF/PPS) laminates impacted at room temperature and $95^{\circ} \mathrm{C}$ and $125^{\circ} \mathrm{C}$. The results showed that stiffness and degree of energy based damage for this material decreased with increase in temperature as the impact behaviour transformed from brittle to ductile.

The effects of fiber bridging on delamination behaviour in multidirectional laminates were investigated by (Gong et al. 2017) and (Riccio et al. 2017). They proposed delamination propagation criterion taking account of real variation on the critical fracture energy associated with the fibre bridging failure. The presented results demonstrated the pronounced effects of fibre bridging on the delamination growth.

A literature review has confirmed that many researchers have experimentally investigated the effect of temperatures on the behavioural response of laminated composites. However, very few studies have simulated damage under different thermal conditions. This paper addresses that deficiency and presents a new approach of assessing incremental damage and takes into account thermal stress effect on delamination growth. 


\section{Interface constitutive model without temperature dependency}

Cohesive zone models are used to describe progressive damage in composite materials. Based on interfacial fracture mechanics, the fracture process zone ahead of a crack tip is illustrated as shown in Figure 1. In composite laminates the crack tip can be represented by a cohesive zone which depends on the separation displacement between two substrates. The required stress to resist this separation is determined as a function of the separation displacement using, for example, the bi-linear traction-separation constitutive law, see Figure 2, which is the most widely used to describe fracture behaviour in an interface element (Jousset and Rachik 2014).
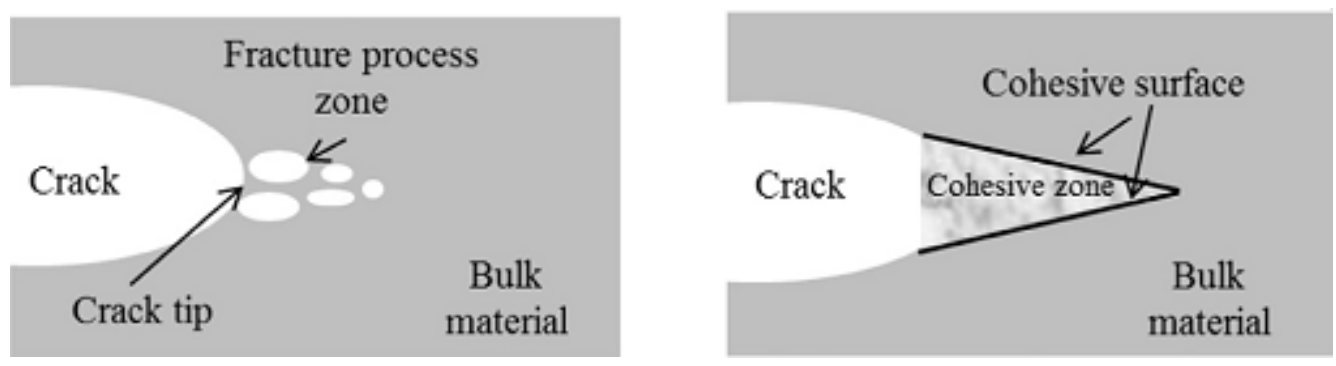

Figure 1 (a) Fracture process zone, and (b) Equivalent cohesive zone (Jousset and Rachik 2014)

(a)

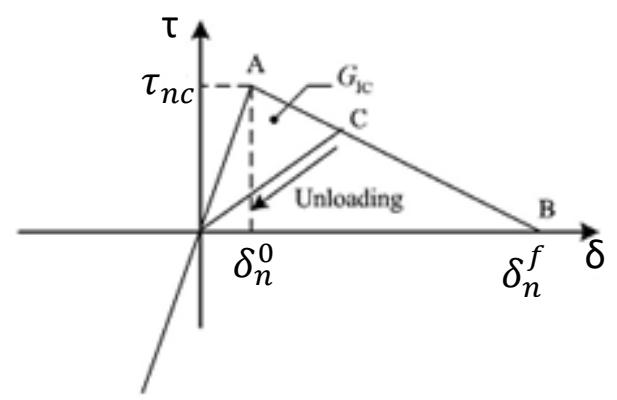

(b)

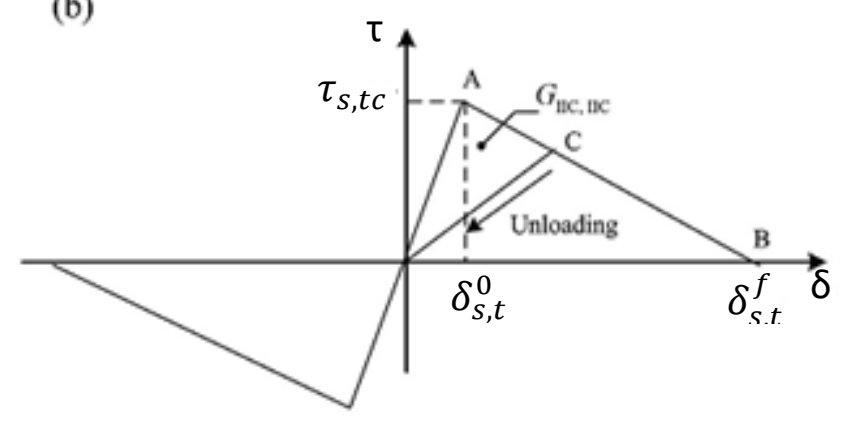

Figure 2 Bi-linear traction-separation law under tension and compression (a) Mode I and (b) Mode II (Zhang et al. 2017)

The three active components of traction are Mode I, normal stress which is in a through thickness direction, and two shear tractions; Mode II and Mode III governed by separation displacement given by the traction-separation law. The elastic behaviour of the cohesive zone can be described as Equation 1;

$$
\left[\begin{array}{l}
\tau_{n} \\
\tau_{s} \\
\tau_{t}
\end{array}\right]=\left[\begin{array}{ccc}
k_{n n} & 0 & 0 \\
0 & k_{s s} & 0 \\
0 & 0 & k_{t t}
\end{array}\right]\left[\begin{array}{l}
\delta_{n} \\
\delta_{s} \\
\delta_{t}
\end{array}\right]
$$


where $\tau_{n}, \tau_{s}, \tau_{t}$ are the normal, shear and tear stresses respectively, and $\delta$ and $k$ are the separation displacement and the initial stiffness of the interface of each mode, respectively.

As shown in Figure 2, the bi-linear traction-separation law under typical pure modes initially assumes a linear elastic behaviour followed by the initiation and evolution of damage. The softening initiation displacements are calculated as ;

$\delta_{n}^{0}=\tau_{n c} /_{k_{n n}}, \quad \delta_{s}^{0}=\tau_{s c} /_{k_{s s}}, \quad \delta_{t}^{0}=\tau_{t c} /_{k_{t t}}$

The final separation or complete debonding is defined as ;

$\delta_{n}^{\mathrm{f}}=\frac{2 G_{I C}}{\tau_{n c}}, \quad \delta_{s}^{\mathrm{f}}=\frac{2 G_{I I C}}{\tau_{s c}}, \delta_{t}^{\mathrm{f}}=\frac{2 G_{I I I C}}{\tau_{t c}}$

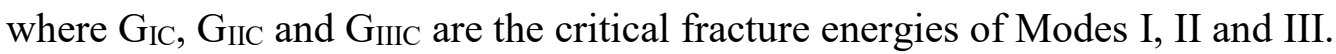

\subsection{Prediction of onset of mixed mode softening}

The damage onset of the cohesive element under pure Mode I, II or III loading, can be determined in a straightforward manner using a maximum traction stress criterion for each mode, obtained by comparing the traction components with allowable stress. However, when using this criterion to determine damage onset under mixed-mode loading poor results are obtained, because softening behaviour may appear before any stress components. Therefore, the interactions between stress components of each mode should be taken into account to determine initiation of delamination damage.

The quadratic nominal stress criterion to predict the delamination onset under mixed mode loading, is one of the most frequently adopted failure criteria (Camanho et al. 2003). This criterion has been successfully utilized by many researchers, and is written as;

$$
\left(\frac{\left\langle\tau_{n}\right\rangle}{\tau_{n c}}\right)^{2}+\left(\frac{\tau_{s}}{\tau_{s c}}\right)^{2}+\left(\frac{\tau_{t}}{\tau_{t c}}\right)^{2} \geq 1
$$

Figure 3 illustrates the mixed-mode bi-linear traction-separation law for the interface element. The effective relative displacement, $\delta_{m}$, is defined as;

$$
\delta_{m}=\sqrt{\left\langle\delta_{n}\right\rangle^{2}+\delta_{s}^{2}+\delta_{t}^{2}}
$$

Equation 3 can also be written as; 


$$
\left.\delta_{m}=\sqrt{\left\langle\delta_{n}\right\rangle^{2}+\delta_{\text {shear }}^{2}} \quad \text { (where } \delta_{\text {shear }}^{2}=\delta_{s}^{2}+\delta_{t}^{2}\right)
$$

where the operator $\langle x\rangle$ is defined as;

$$
\langle x\rangle= \begin{cases}x, & x>0 \\ 0, & x \leq 0\end{cases}
$$

Using the same interface stiffness for Modes I, II and III and a quadratic nominal stress criterion, the onset of softening displacement under tension mixed-mode conditions $\left(\delta_{n}>0\right)$, see Figure 2, is obtained as (Zhang et al. 2017);

$$
\delta_{m}^{0}=\delta_{n}^{0} \delta_{\text {shear }}^{0} \sqrt{\frac{1-\left(\delta_{\text {shear }} / \delta_{n}\right)^{2}}{\left(\delta_{\text {shear }}^{0}\right)^{2}+\left(\delta_{\text {shear }} / \delta_{n}\right)^{2}\left(\delta_{n}^{0}\right)^{2}}} \quad \delta_{1}>0
$$

In Equation (6), the pure Mode I can be obtained by setting $\delta_{\text {shear }} / \delta_{n}=0$, (i.e., $\delta_{m}^{0}=\delta_{n}^{0}$ ). The mixed-mode is reduced to the shear model when the shear displacement $\left(\delta_{\text {shear }}\right)$ is much larger than the normal displacement, i.e. $\delta_{\text {shear }} / \delta_{n} \Rightarrow \infty$.

When the cohesive zone undergoes a through-thickness compression, the stiffness degradation of the interface element will occur only in a shear mode (Mode II or Mode III), whereas there is no damage initiation and propagation of Mode I, see Figure 2. Therefore, the onset of damage under mixed a mode occurs if $\delta_{n}<0$ is $\delta_{\text {shear }}^{0}$.

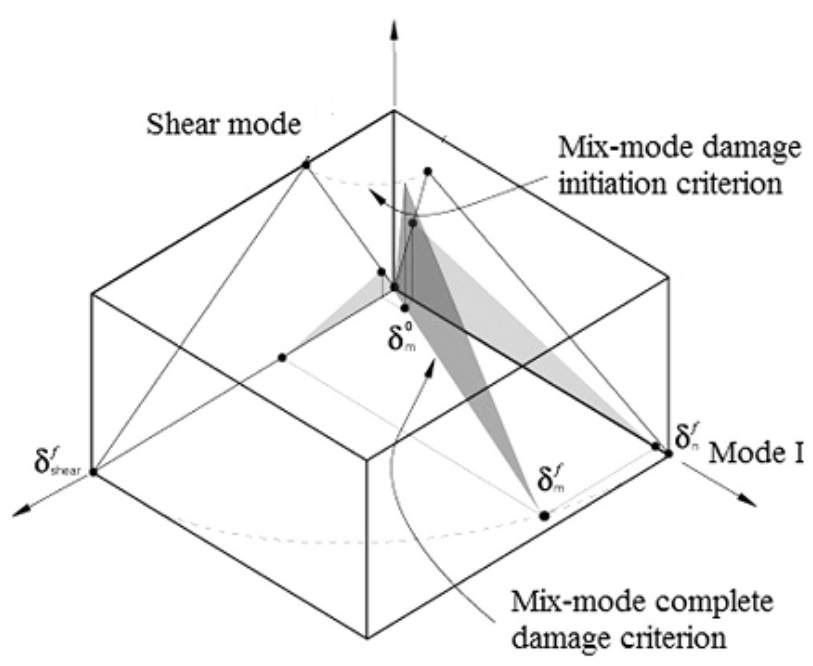

Figure 3 Mixed-mode bi-linear traction-separation law of interface element (Camanho et al. 


\subsection{Damage propagation prediction}

Damage growth prediction under mixed-mode loading is predicted using the energy release rate during loading and unloading, and fracture toughness.

The power law criterion is most widely used to predict damage growth under mixed-mode loading. This criteria is based on the concept of interaction between the energy release rates (Camanho et al. 2003), and is written as;

$$
\left(\frac{G_{I}}{G_{I C}}\right)^{\beta}+\left(\frac{G_{I I}}{G_{I I C}}\right)^{\beta} \geq 1
$$

where $\beta=1$. $G_{I}$ and $G_{I I}$ are energy release rate of Modes I, II respectively.

The effective displacement at complete failure $\left(\delta_{m}^{f}\right)$ of a mixed mode is obtained based on a quadratic nominal stress criterion and the power interaction law of energy (Equation 7). Therefore, the final displacement of a mixed-mode under tension $\left(\delta_{n}>0\right)$ is expressed as;

$$
\delta_{m}^{f}=\frac{2\left(1+\left(\delta_{\text {shear }} / \delta_{\mathrm{n}}\right)^{2}\right) / k \delta_{m}^{0}}{\sqrt{\left(1 / G_{I C}\right)^{2}+\left(\left(\delta_{\text {shear }} / \delta_{\mathrm{n}}\right)^{2} / G_{I I C}\right)^{2}}}
$$

where $k$ is the initial stiffness, $\mathrm{G}_{\mathrm{IC}}$, and $\mathrm{G}_{\mathrm{IIC}}$ are the critical fracture energies of Modes I, II.

Under through-thickness compression $\left(\delta_{n}<0\right)$, the effective displacement at complete failure $\left(\delta_{m}^{f}\right)$ is;

$$
\delta_{m}^{f}=\sqrt{\left(\delta_{\mathrm{s}}^{f}\right)^{2}+\left(\delta_{\mathrm{t}}^{f}\right)^{2}}
$$

\section{Thermal stress effect}

When a mechanical force acts on the composite materials concurrent with a temperature change, the nominal strain contribution due to the temperature change should be added to the nominal strain due to the internal stress. An incremental damage evolution law will be developed to take into consideration the mechanical effects of change in temperature of an interface element. Based on the Helmholtz free energy density, the free potential energy $(\psi)$ is a function of the cohesive zone displacements, evolution of damage, and the effect of temperature across the interface $(\Delta T)$, and can be written as;

$$
\psi\left(\delta_{i}, D, \Delta T\right)=\frac{1}{2}(1-D) k_{i}\left(\delta_{i}-\alpha \Delta T\right)^{2}
$$


Where $(i=n, s, t), \alpha$ is thermal expansion coefficient, and $D$ is damage parameter which is calculated as;

$$
D=\frac{\delta_{m}^{f}\left(\delta_{m}-\delta_{m}^{o}\right)}{\delta_{m}\left(\delta_{m}^{f}-\delta_{m}^{o}\right)}
$$

The traction components are obtained by differentiating the potential energy relative to interface displacement as;

$$
\tau_{i}=\frac{\partial \psi}{\partial \delta_{i}}=(1-D) k_{i}\left(\delta_{i}-\alpha \Delta T\right)
$$

and the thermodynamic conjugate force is derived relative to damage variable (D);

$$
\mathbb{C}=-\frac{\partial \psi}{\partial D}=\frac{1}{2} k_{i}\left(\delta_{i}-\alpha \Delta T\right)^{2}
$$

The damage function is defined as:

$$
\mathcal{F}(\mathbb{C}, D)=\mathbb{C}-\mathcal{R}(D)
$$

The function $\mathcal{R}(D)$ is the resistance to the crack propagation, and written as;

$$
\mathcal{R}(D)=\frac{1}{2}(1-D) k_{i}\left(\delta_{i}-\alpha \Delta T\right)^{2}
$$

The incremental damage evolution law is calculated using the consistency condition $\dot{\mathcal{F}}=0$;

$$
\frac{\partial \mathbb{C}}{\partial \delta_{i}} \partial \delta_{i}-\frac{\partial \mathcal{R}(D)}{\partial D} \partial D=0
$$

Therefore, the new incremental damage including the effect of temperature change is given by;

$$
\partial D=\frac{\sum_{i=1}^{3} k_{i}\left(\delta_{i}-\alpha \Delta T\right)}{\sum_{i=1}^{3} \frac{1}{2} k_{i}\left(\delta_{i}-\alpha \Delta T\right)^{2}} \partial \delta_{i}
$$

\section{The effectiveness of new approach}

\subsection{Three-point bending specimen}

(Jia et al. 2018) carried out static three-point bending tests on high strength carbon fibre reinforced plastic using MTS mechanical tests with a $1 \mathrm{kN}$ load cell. The tests were performed on specimens with length along the longitudinal fibre of $101.6 \mathrm{~mm}$, across the specimen 12.7 
$\mathrm{mm}$ and height of $1.5 \mathrm{~mm}$, see Figure 4 . The material properties of high strength carbon fibres reinforced polymer at room temperature are listed in Table 1.

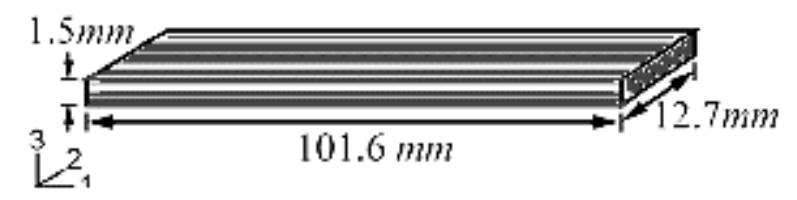

Figure 4 Specimen dimensions (Jia et al. 2018)

Table 1 The material properties of high strength carbon fibres reinforced polymer (Jia et al. 2018)

\begin{tabular}{c|c} 
Modulus $(\mathrm{Pa})$ & $227 \times 10^{9}$ \\
\hline Tensile strength $(\mathrm{Pa})$ & $2.8 \times 10^{9}$ \\
Poisson's ratio & 0.3 \\
Linear thermal expansion coefficient, \\
$\times 10^{-6 /{ }^{\circ} \mathrm{C}}$ & 4
\end{tabular}

(Jia et al. 2018) performed mechanical experiments over a temperature range from $60^{\circ} \mathrm{C}$ to $60^{\circ} \mathrm{C}$ in an environmental chamber with temperature accurate to $\pm 1^{\circ} \mathrm{C}$. Five specimens were examined and held for 20 minutes in the chamber to reach a uniform temperature prior to the experimental tests. A quasi-static test was conducted on all specimens with a constant strain rate of 0.01 , at the middle of the span along the specimen's length. The force-displacement responses of the three-point bending tests conducted at the various temperatures were measured. These results are used below to validate the predictions of the model being developed.

\section{Numerical simulation}

In this section, the experimental tests of (Jia et al. 2018) are simulated to validate the new incremental damage evolution law for interface elements. The incremental damage model developed was implemented in ABAQUS/Standard software using a user-defined material model via the UMAT subroutine. 
The specimen was divided into two sub-laminates, each $0.75 \mathrm{~mm}$ thick, and connected to each other by a cohesive element via a 'Tie' interaction. The materials properties of interfacing element, used in simulation, are listed in Table 2. According to (Zou and Hameed 2018), an interface stiffness of $1 \times 10^{14} \mathrm{~N} / \mathrm{m}^{3}$ was adopted in the finite element model. The element type adopted for the layers was the 4-node bilinear, CPS4, and for the adhesive layer the 4-node cohesive element COH2D4 was used. For all elements, the size was $0.1 \mathrm{~mm}$. The finite element model is illustrated in Figure 5.

Table 2 Material properties of the interface element (Shi et al. 2012)

\begin{tabular}{cccc}
\hline$\tau_{\mathrm{nc}}$ & $\tau_{\mathrm{sc}}=\tau_{\mathrm{tc}}$ & $\mathrm{G}_{\mathrm{IC}}$ & $\mathrm{G}_{\mathrm{IIC}}=\mathrm{G}_{\mathrm{IIIC}}$ \\
$(\mathrm{MPa})$ & $(\mathrm{MPa})$ & $\left(\mathrm{J} / \mathrm{m}^{2}\right)$ & $\left(\mathrm{J} \mathrm{m}^{2}\right)$ \\
\hline 62.3 & 92.3 & 280 & 790 \\
\hline
\end{tabular}

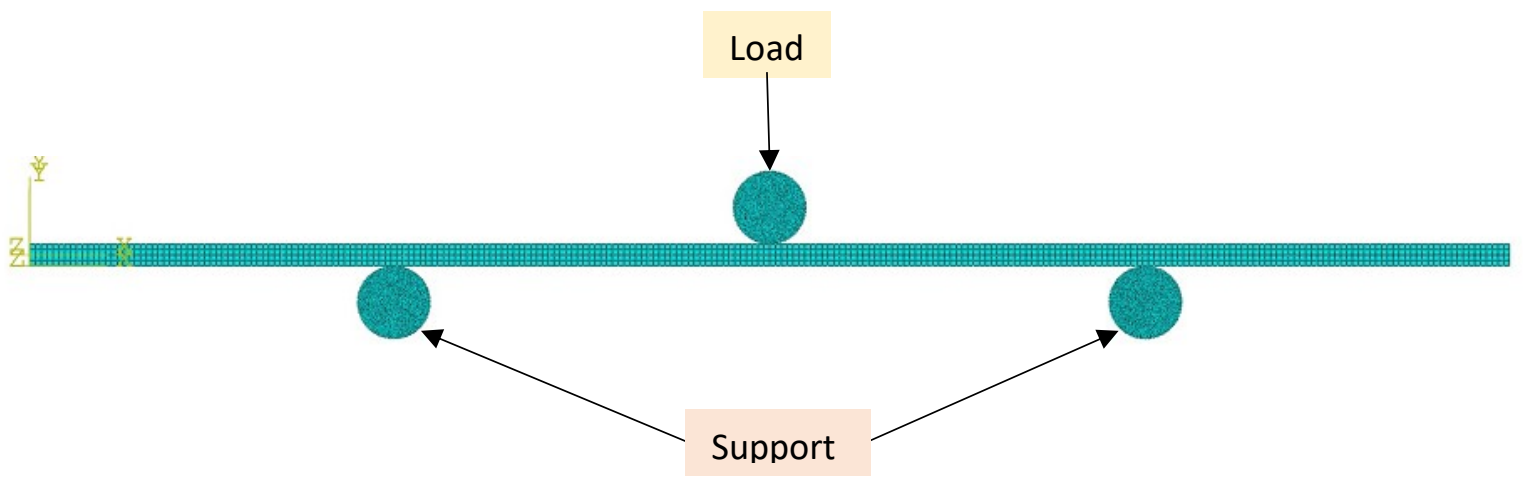

Figure 5 Finite element model of three-point bending specimen

When the specimen was tested under different temperature conditions, the total traction stress of the interface element was a combination of thermal stress and normal /shear stress for each mode. The damage initiation stress was updated based on; $\tau_{\text {inew }}=\tau_{i}-\tau_{\text {thermal }}$, so that $\tau_{\text {thermal }}=k \alpha \Delta T$. Thus if the temperature changed resulting in a change in traction stress, the fracture energy was also affected.

Figure 6 is a schematic of the bilinear traction separation law at low and room temperature. It is clear that the traction at onset of damage increased when the specimen was at a low temperature. The fracture energy increased by $\Delta G=\frac{1}{2} \delta^{f} \delta^{c}\left[\left(\frac{\tau_{c}^{\text {new }}}{\tau_{c}}\right)^{2}-1\right]$. 
In addition, the damage initiation displacement and final failure displacement increased to $\delta_{\text {new }}^{c}=\left(\tau_{c}^{\text {new }} / \tau_{c}\right) \delta^{c}$, and $\delta_{\text {new }}^{f}=\left(\tau_{c}^{\text {new }} / \tau_{c}\right) \delta^{f}$, respectively. The energy absorption is the area below the traction-separation curve. Thus, according to the traction separation law the energy absorbed is less at a higher temperature due to the cohesive behaviour. This is shown as $\Delta G$ in the figure.

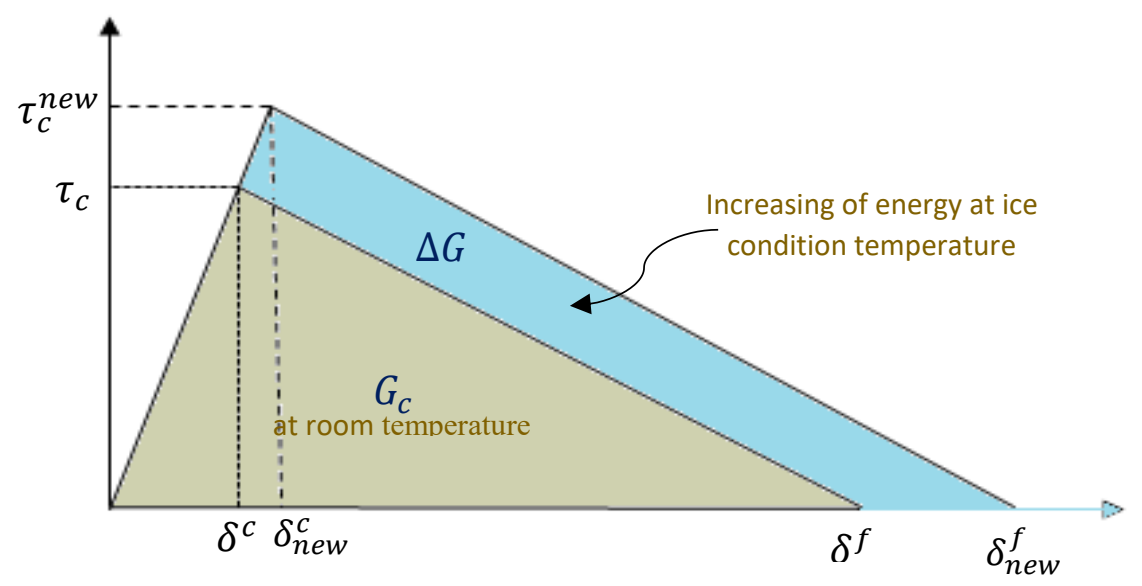

Figure 6 Schematic traction-separation law

Figure 7 shows the force-displacement curves for all the specimens under three different thermal conditions (i.e. $60^{\circ} \mathrm{C},-20^{\circ} \mathrm{C}$ and $-60^{\circ} \mathrm{C}$ ). It can clearly be observed that the loaddisplacement response behaviour using this new approach is similar to the experimental data and both sets of curves have a linear elastic section followed by a force drop. 


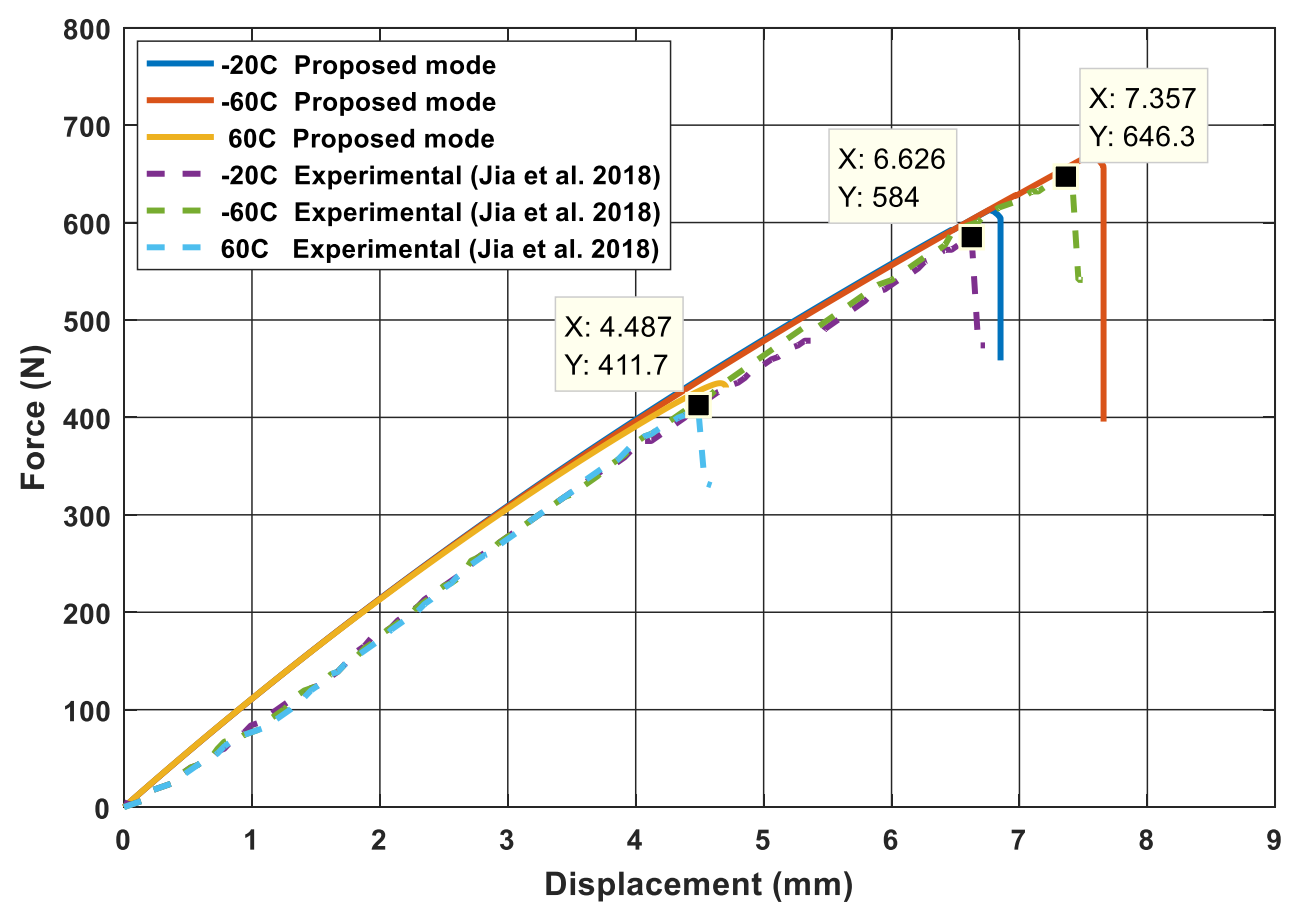

Figure 7 Force-displacement curve of three-point bending specimen

\subsection{Double Cantilever Beam (DCB)}

Inter-laminar damage in composite structures is a frequent failure mode which has a significant effect on strength, stiffness and structural integrity. Thus, the understanding of resistance to delamination fracture in composite materials is particularly important. The critical fracture energy of Mode I can be measured experimentally using a double cantilever beam (DCB). This energy will change when the composite material is determined under different environmental conditions, i.e. different temperatures.

Many researchers have experimentally measured fracture toughness of unidirectional laminated composites at room and other temperatures, but temperature effects on inter-laminar damage have not been fully investigated numerically.

(Kim HS 1999) investigated the fracture energy of Carbon/Epoxy composites at $-100^{\circ} \mathrm{C}$, room temperature and $150^{\circ} \mathrm{C}$, using a DCB with pre-cracked interface, $\left[0_{12} / / 0_{12}\right]$. A schematic of the DCB specimen, including dimensions and delamination between sub-laminates, is shown in Figure 8 . The authors performed the tests using a servo-hydraulic machine to provide displacement control, and a thermostatic chamber which could accurately maintain the temperature at any temperature between $-180^{\circ} \mathrm{C}$ and $320^{\circ} \mathrm{C}$. The specimens were kept for one 
hour in the thermostatic chamber to reach a homogeneous distribution of temperature before the tensile testing.

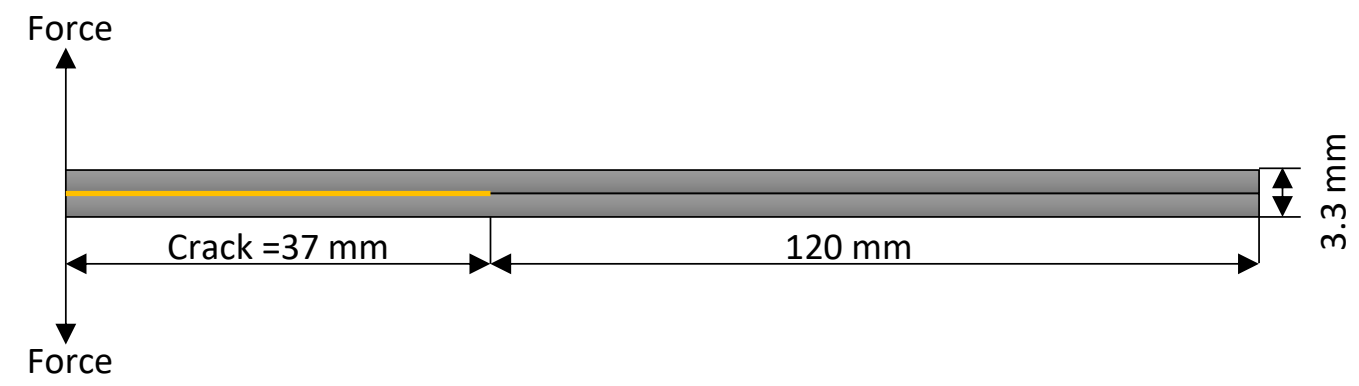

Figure 8 DCB specimen dimensions

The morphologies of the fracture surface when using the DCB specimen type $[0 / / 0]$ were reported by (Kim HS 1999), and are shown in Figure 9. It is clearly seen that at a temperature of $-100^{\circ} \mathrm{C}$, the fiber breakage and fiber bridging happened at onset and propagation of damage, while the fiber bridging occurred just at the initiation, see Figure 9a. When the specimens were examined at a high temperature $\left(150^{\circ} \mathrm{C}\right)$, the damage started in the matrix followed by fiber bridging which has a significant effect on the inter-laminar damage growth as shown in Figure 9b. Therefore, the failure occurred at a smaller fracture energy because the matrix critical energy is relatively low. This explains why the fracture toughness at room temperatures is lower than at cryogenic temperatures. 


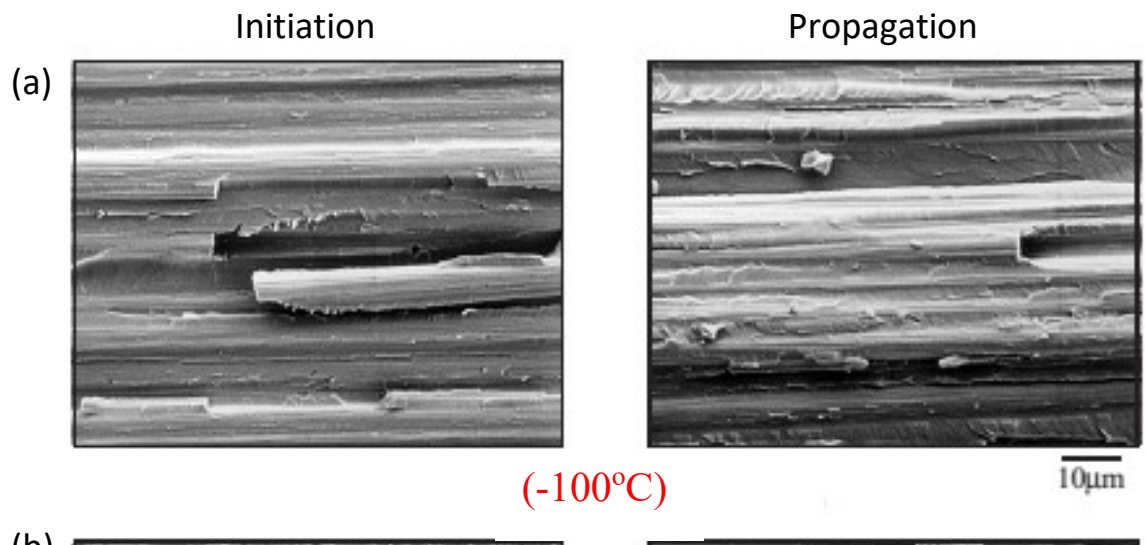

(b)
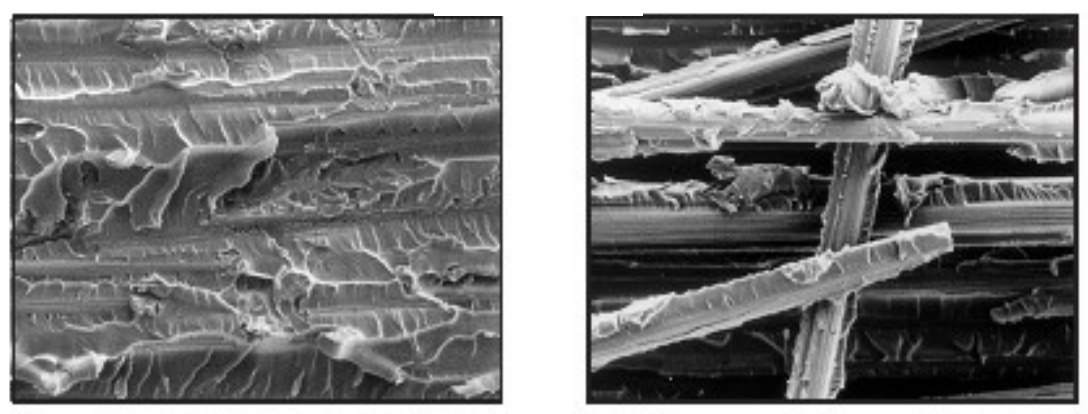

$\left(150^{\circ} \mathrm{C}\right)$

Figure 9 Images of fracture surfaces for unidirectional specimen (Kim HS 1999)

In the simulation model, the new approach was applied to investigate fracture energy and response behaviour of $\mathrm{DCB}$ at various temperatures. The numerical model was built in ABAQUS and again used element type $\mathrm{COH} 2 \mathrm{D} 4$ for the interface elements, and element type CPS4 for the sub-laminates, both types had element size $0.1 \mathrm{~mm}$. The interface stiffness used in the modelling was $1 \times 10^{14} \mathrm{~N} / \mathrm{m}^{3}$.

The force-displacement curves obtained for high $\left(150^{\circ} \mathrm{C}\right)$ and low $\left(-100^{\circ} \mathrm{C}\right)$ temperatures are presented in Figures 10 and 11. It was recognized that the change in temperature had a noticeable effect on damage initiation and propagation. The predicted force required for failure in the unidirectional specimen at the higher temperature was $52 \mathrm{~N}$, less than the $60 \mathrm{~N}$ required at the lower temperature. At $150^{\circ} \mathrm{C}$, the predicted displacement at which the peak force occurs is very close to the measured value; both $1.6 \mathrm{~mm}$. The predicted results compared well with Kim's measured data. 


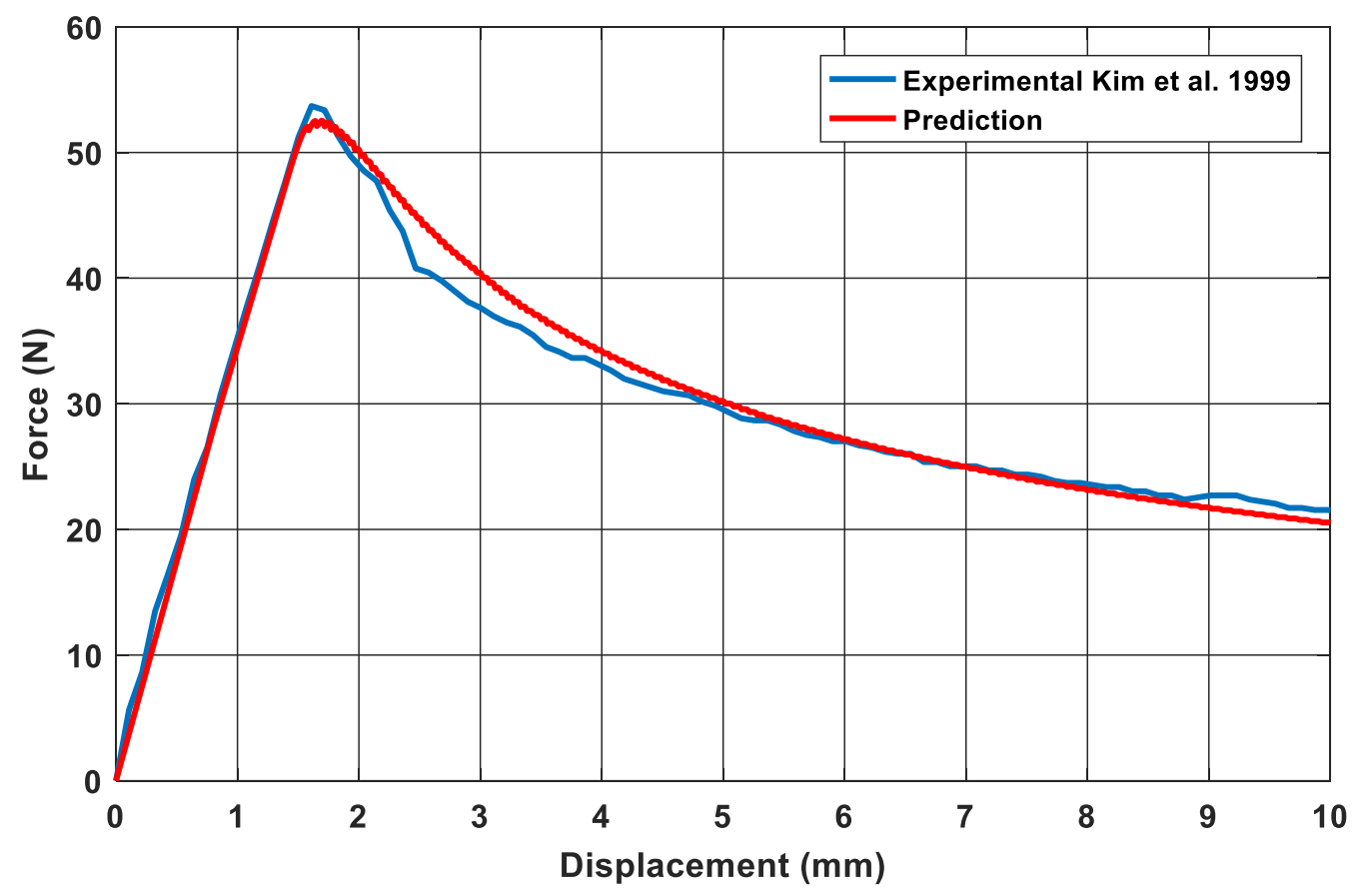

Figure 10 Force-displacement curve at high temperature $\left(150^{\circ} \mathrm{C}\right)$

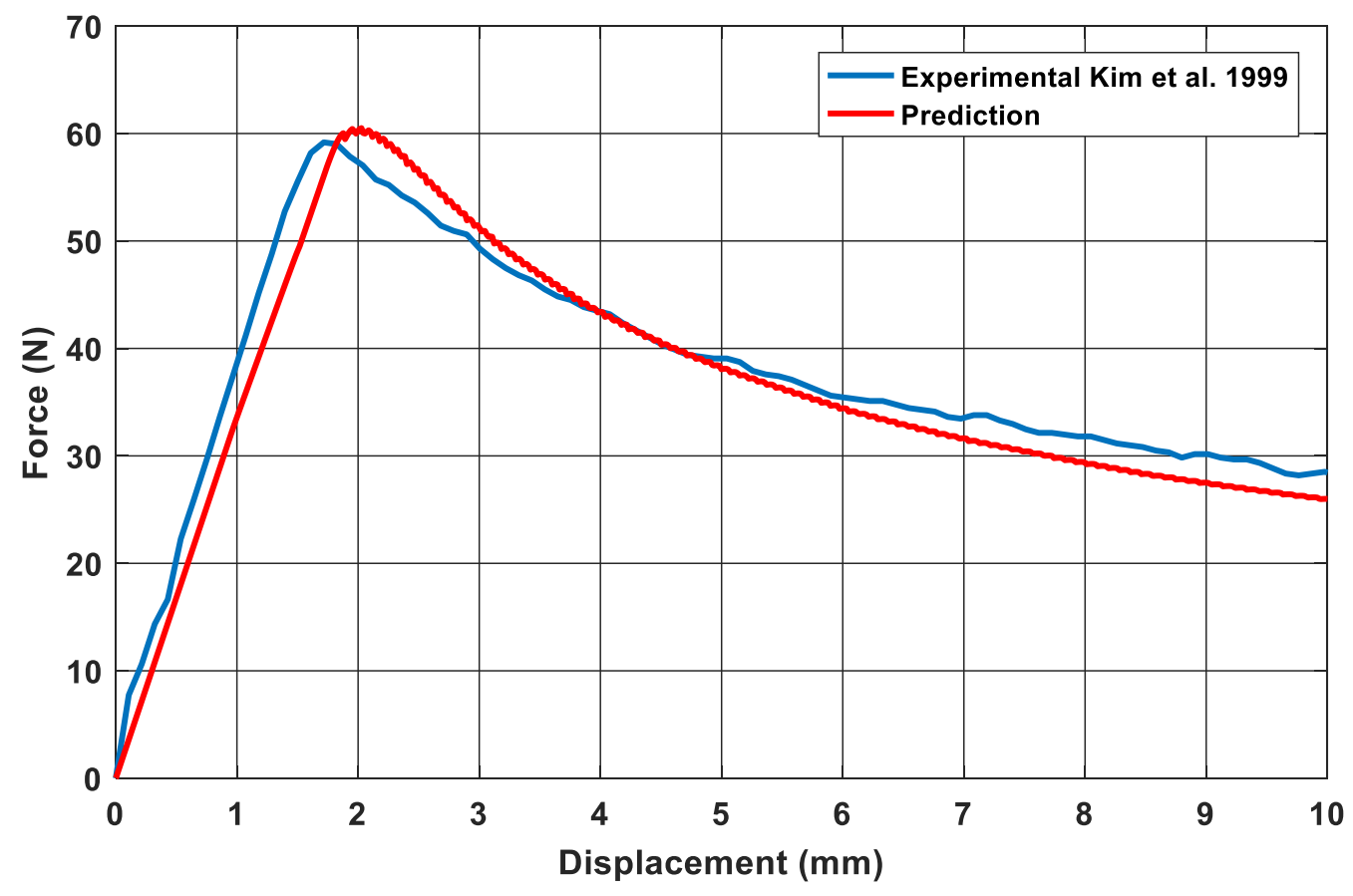

Figure 11 Force-displacement curve at low temperature $\left(-100^{\circ} \mathrm{C}\right)$

The peaks move in the same direction as the temperature decreases to $-100^{\circ} \mathrm{C}$, and agreement remains good; $2.0 \mathrm{~mm}$ for the predicted and $1.75 \mathrm{~mm}$ for the measured. We see that predicted values and experimental results reported by (Kim HS 1999) are in good agreement. 


\section{Conclusions}

The objective of this research was and remains to develop a damage model that includes the effect of temperature on the unidirectional laminated composite response. The numerically predicted results were in a good agreement with experimental data and revealed the underlying toughening mechanisms as an increase in the damage initiation stress at cryogenic temperatures

by $\tau_{\text {thermal }}=k \alpha \Delta T$, which enhanced the fracture energy by $\Delta G=\frac{1}{2} \delta^{f} \delta^{c}\left[\left(\frac{\tau_{c}^{\text {new }}}{\tau_{c}}\right)^{2}-1\right]$. In addition, the damage onset and final failure displacement were changed with the embrittlement of the matrix in unidirectional composite materials at temperatures greater than room temperature, together with the inter-laminar thermal stresses generated in the interface element facilitate the initiation and propagation of damage. 


\section{References}

Amaro, A. M., P. N. B. Reis, and M. A. Neto. 2016. Experimental study of temperature effects on composite laminates subjected to multi-impacts. Composites Part B-Engineering 98:23-29.

Boominathan, R., V. Arumugam, C. Santulli, A. A. P. Sidharth, R. A. Sankar, and B. T. N. Sridhar. 2014. Acoustic emission characterization of the temperature effect on falling weight impact damage in carbon/epoxy laminates. Composites Part B-Engineering 56:591-598.

Camanho, P. P., C. G. Davila, and M. F. de Moura. 2003. Numerical simulation of mixed-mode progressive delamination in composite materials. Journal of Composite Materials 37 (16):1415-1438.

Gong, Y., L. B. Zhao, J. Y. Zhang, Y. N. Wang, and N. Hu. 2017. Delamination propagation criterion including the effect of fiber bridging for mixed-mode $\mathrm{I} / \mathrm{II}$ delamination in CFRP multidirectional laminates. Composites Science and Technology 151:302-309.

Jia, Z. A., T. T. Li, F. P. Chiang, and L. F. Wang. 2018. An experimental investigation of the temperature effect on the mechanics of carbon fiber reinforced polymer composites. Composites Science and Technology 154:53-63.

Jousset, P., and M. Rachik. 2014. Comparison and evaluation of two types of cohesive zone models for the finite element analysis of fracture propagation in industrial bonded structures. Engineering Fracture Mechanics 132:48-69.

Kim HS, W. W., Taka Y. 1999. Effects of temperature and fiber orientation on the mode I interlaminar fracture toughness of carbon/epoxy composites. Paper read at Proc 12th Int Conf Compos Mater, ICCM 12

Reed, R. P., and M. Golda. 1994. Cryogenic Properties of Unidirectional Composites. Cryogenics 34 (11):909-928.

Reinoso, J., G. Catalanotti, A. Blazquez, P. Areias, P. P. Camanho, and F. Paris. 2017. A consistent anisotropic damage model for laminated fiber-reinforced composites using the 3D-version of the Puck failure criterion. International Journal of Solids and Structures 126:37-53.

Riccio, A., A. Russo, A. Sellitto, and A. Raimondo. 2017. Development and application of a numerical procedure for the simulation of the "Fibre Bridging" phenomenon in composite structures. Composite Structures 168:104-119.

Rio, T. G. D., R. Zaera, E. Barbero, and C. Navarro. 2005. Damage in CFRPs due to low velocity impact at low temperature. Composites Part B-Engineering 36 (1):41-50.

Shi, Y., T. Swait, and C. Soutis. 2012. Modelling damage evolution in composite laminates subjected to low velocity impact. Composite Structures 94 (9):2902-2913.

Wang, Y., J. P. Zhang, G. D. Fang, J. Z. Zhang, Z. G. Zhou, and S. Y. Wang. 2018. Influence of temperature on the impact behavior of woven-ply carbon fiber reinforced thermoplastic composites. Composite Structures 185:435-445.

Zhang, C., J. L. Curiel-Sosa, and T. Q. Bui. 2017. A novel interface constitutive model for prediction of stiffness and strength in 3D braided composites. Composite Structures 163:32-43.

Zou, Z. M., and M. Hameed. 2018. Combining interface damage and friction in cohesive interface models using an energy based approach. Composites Part a-Applied Science and Manufacturing 112:290-298. 